\title{
Growth and carcass characteristics of male dairy calves on a yeast culture-supplemented diet
}

\author{
H.H. Titi ${ }^{1 \#}$, A.Y. Abdullah ${ }^{2}$, W.F. Lubbadeh ${ }^{1}$ and B.S. Obeidat ${ }^{2}$ \\ ${ }^{1}$ Department of Animal Production, Faculty of Agriculture / University of Jordan, Amman 11942-Jordan \\ ${ }^{2}$ Department of Animal Production, Faculty of Agriculture / Jordan University of Science and Technology, \\ P.O. Box 3030, Irbid 22110, Jordan
}

\begin{abstract}
This experiment was carried out to study the effect of the inclusion of a yeast culture in the diet of feeder dairy calves on their growth and carcass characteristics. Thirty male Friesian calves were randomly allocated to two groups of 15 each (treatment and control). The calves were fed a total mixed ration for a period of 294 days and then slaughtered to obtain carcass measurements. The yeast culture was added to the diet of the treatment group at a level of $20 \mathrm{~kg}$ yeast culture/ton of feed. The addition of the yeast culture did not affect final weight, average gain or average daily gain, but reduced total and daily dry matter intakes. Feed conversion ratio was not affected by treatment. Yeast culture supplementation had no effect on fasting weight or cold carcass weight, dressing percentage nor on non-carcass components. Differences in back-fat thickness and in the weight and percentage of carcass cuts were not significant between treatments. Similarly, carcass characteristics and quality measures did not show any significant differences between treatments. In this experiment the inclusion of a yeast culture in the finishing off diet of dairy calves had no effect on their growth rate, feed conversion ratio, carcass characteristics or meat quality.
\end{abstract}

Keywords: Yeast, dairy calves, growth performance, carcass quality

\# Corresponding author. E-mail: htiti@ju.edu.jo

\section{Introduction}

A wide variety of feed additives to manipulate rumen activity is available on the market. For more than 10 years yeast cultures have been used as alternatives to antimicrobial additives in ruminant diets, and have shown to affect the rumen in several ways. Yeast cultures were found to modify rumen fermentation by increasing the number of ruminal bacteria and to stimulate animal growth when fed to lactating and growing ruminants (Beauchemin et al., 2003). Furthermore, the addition of yeast cultures to diets of feeder calves, growing steers, beef bulls and beef cattle increased dry matter intake and/or weight gain (Cole et al., 1992; Mir \& Mir, 1994; Olson et al., 1994).

Several factors are likely to affect the response to yeast culture supplementation, including type of forage fed, type of diet such as the feeding of a total mixed ration (TMR) or not, forage-to-concentrate ratio and the stage of lactation in dairy cows (Piva et al., 1993). Feeding high-grain diets to ruminants to increase energy density has resulted in negative associative effects on fibre digestion in the rumen. Harrison et al. (1988) concluded that rumen fermentation was more stable in dairy cows fed high concentrate diets supplemented with yeast culture than without the supplement, and several studies reported improved performance of dairy and beef cattle fed high-concentrate diets supplemented with yeast cultures (Higginbotham et al., 1994; Mir \& Mir, 1994; Olson et al., 1994). Furthermore, inclusion of yeast culture in the diets of dairy cows produced variable responses in tolerance to heat stress (Higginbotham et al., 1994).

Dairy beef is considered the main source of meat in many parts of the world, especially in the Middle East. Due to differences in their genetic makeup and growth performance, meat traits are very different between beef and dairy calves. However, very few studies have been conducted to investigate the effect of yeast culture supplementation on the performance and carcass characteristics of dairy beef calves. Such traits might be altered by adding yeast to the finishing diet of the growing calf. Moreover, hot environmental conditions are prevalent in several parts of Middle East countries and that might interfere with the rearing and fattening of livestock in these areas. Therefore, this research was carried out to study the effect of including a yeast culture in the diet of feeder Friesian male calves on their growth and carcass traits. 


\section{Materials and Methods}

Thirty weaned Friesian male calves, $4 \pm 0.6$ months of age and weighing $64.0 \pm 3.1 \mathrm{~kg}$, were used in the study. The study was conducted in the Jordan Valley located at $32^{\circ} 10^{\prime} \mathrm{N}$ latitude and $35^{\circ} 37^{\prime} \mathrm{E}$ longitudes with an elevation of $-230 \mathrm{~m}$ below sea level. They trial started in January and continued for 294 days. Maximum temperature from May to October ranged between 35 and $42{ }^{\circ} \mathrm{C}$. The calves were weighed at the beginning of the experiment, stratified according to body weight and then allocated randomly to one of two treatments, 15 animals per treatment. The number of animals used, was determined on the basis of the published literature pertaining to the parameters studied, using the sample size equation of Steel \& Torrie (1986). The calves were housed individually and were weighed every 28 days. Calves in the control group were fed a TMR, while the treatment group received the same diet supplemented with a yeast culture ("XP" Yeast Culture, Diamond V. Mills, Cedar Rapids, IA, USA). The yeast culture was included at a level of 20 $\mathrm{kg} / \mathrm{ton}$ feed, according to the manufacturer's recommendations. The chemical composition of the yeast culture was stated as $\geq 120 \mathrm{~g}$ crude protein $/ \mathrm{kg}, \leq 30 \mathrm{~g}$ crude fat $/ \mathrm{kg}$ and $\geq 65 \mathrm{~g}$ crude fibre $/ \mathrm{kg}$. The yeast culture was processed along with the other TMR ingredients, but was first hand-mixed with the micro component mixture of the diet before being placed in a horizontal mixer for complete mixing with the other diet ingredients. Ingredient composition and chemical analysis of the diet are presented in Table 1.

Table 1 Ingredients and chemical composition ( \pm s.d.) of the diet used in the experiment

\begin{tabular}{ll}
\hline & Composition \\
\hline Ingredients $(\mathrm{g} / \mathrm{kg})$ & 615 \\
Barley grain & 100 \\
Soyabean meal & 100 \\
Wheat bran & 150 \\
Lucerne hay & 10 \\
Dicalcium phosphate & 14 \\
Limestone & 10 \\
Salt & 1.0 \\
Vitamin/mineral premix* & \\
Chemical composition $(\mathrm{g} / \mathrm{kg})(\mathrm{DM}$ basis $)$ & $932 \pm 3.5$ \\
Dry matter & $161 \pm 13.8$ \\
Crude protein & $345 \pm 8.7$ \\
Neutral detergent fibre & $149 \pm 8.9$ \\
Acid detergent fibre & $83 \pm 0.7$ \\
Ash & 10.8 \\
ME** (MJ/kg) &
\end{tabular}

\footnotetext{
* Ruminant Nutristar Premix 0.1\% provides per kg: 3000000 IU vitamin A; 1000000 IU vitamin D3; 10000 IU vitamin E; 1600 mg nicotinic acid; 4000 mg choline chloride; 10000 mg DL-methionine; 5000 mg HCL-lysine; 90000 mg iron; $3000 \mathrm{mg}$ iodine; $1000 \mathrm{mg}$ copper; $50000 \mathrm{mg}$ manganese; $50000 \mathrm{mg}$ zinc; $200 \mathrm{mg}$ selenium; $100000 \mathrm{mg}$ magnesium; $30000 \mathrm{mg}$ phosphorus; $103000 \mathrm{mg}$ calcium; $11200 \mathrm{mg}$ antioxidant (Endox), Star International, 95520 Osny, France. ** Calculated from NRC (2001) values.
}

The diet was mixed daily or every other day before feeding. Feed was introduced gradually over a period of seven days, followed by a further seven days to ensure the adequate adaptation of the rumen microorganisms. The diet was offered ad libitum and was fed once daily in the early morning. Refusals were removed and recorded daily before the next feeding. Fresh, clean water and a mineral supplement were available for the duration of the experiment. Feed samples were taken after each mixing and stored at $-4{ }^{\circ} \mathrm{C}$ pending analyses. Analysis was carried out according to the standard procedures of the AOAC (1990). The Kjeldahl method for nitrogen analysis was used for crude protein determination, using a $1031 \mathrm{Kjaltec}$ analyser (Tecator, Sweden) and multiplying the result by 6.25 . Neutral detergent fibre (NDF) and acid detergent fibre (ADF) were determined according to Van Soest \& Robertson (1980) using the ANKOM 
Fiber Analyzer (ANKOM Technology, Fairport, NY, USA) with the addition of heat-stable $\alpha$-amylase. Total daily feed intake, total gain, average daily gain and feed conversion ratio were calculated.

For the duration of the experiment the animals were kept and treated according to the national code of animal health and care. At the end of the feeding period the calves were slaughtered at a commercial abattoir according to local slaughtering and animal welfare regulations. Before slaughtering the calves were kept overnight with no access to feed, but free access to water. Final fasting weights were recorded prior to slaughter. Calves were stunned by captive bolt and then slaughtered and dressed following normal commercial procedures. After slaughter, the hide, head, feet, internal organs (liver, kidney, heart, lungs, and spleen), gut and stomach compartments, and perirenal fat were removed from the carcass and weighed.

Carcasses were weighed to obtain the hot carcass weight, then chilled and kept at $3{ }^{\circ} \mathrm{C}$ for $24 \mathrm{~h}$ before being weighed again to obtain the chilled carcass weight. Dressing percentage was calculated from the chilled carcass weight expressed as a proportion of final fasting live weight. After chilling, the $\mathrm{pH}$ and temperature of the right $M$. longissmus thoracis muscle in the region of the ninth rib were measured at 2, 4, 7 and $24 \mathrm{~h}$ post mortem. The $\mathrm{pH}$ was measured with a $\mathrm{pH}$ meter $(\mathrm{pH}$ Spear, large screen, waterproof $\mathrm{pH} /$ temperature tester, double injection, Model 35634-40, Eurotech Instruments, Malaysia), while the temperature was measured using a digital thermometer (Electro-term, model TM99A, Cooper Instrument Corporation, CT, USA).

After overnight chilling, the cross-sectional area of the longissimus muscle was traced at a transverse cut between ribs 12 and 13, and the area was subsequently measured using a digital planimeter (Placom KP$90 \mathrm{~N}$, Tokyo, Japan). In addition, the dimensions and fat thickness over this muscle were measured and a $2 \mathrm{~kg}$ sample was excised and used for objective measures of tenderness and other meat quality characteristics.

For meat quality assessments three slices were prepared from each sample to measure colour and cooking loss and for assessing water-holding capacity (WHC), $\mathrm{pH}$ and intramuscular fat. The WarnerBratzler (WB) shear force was measured according to Purchas \& Aungsupakorn (1993). The WHC was measured using the method described by Sañudo et al. (1986) and expressed as a percentage of drip loss.

Six replicates were obtained from each sample to measure shear force and each was sheared twice using a WB shear blade (Warner-Bratzler meat shear, G-R Manufacturing Co., USA, Salter, Model 235). The average of the two readings was calculated and recorded. All steaks were weighed before and after cooking to calculate cooking losses. At the time of the meat quality measurements, after thawing, the meat $\mathrm{pH}$ was measured in a homogenate of $2 \mathrm{~g}$ (using Ultra Turrax $\mathrm{T} 8$ homogeniser). The $\mathrm{pH}$ of the homogenate was measured at around $20{ }^{\circ} \mathrm{C}$ using the same $\mathrm{pH}$ meter as used for measuring the $\mathrm{pH}$ of the carcasses. The surface colour of the muscles was recorded in samples (Geesink et al., 2000) using a ColorTec-PCM/PSM Color Meter with a $12 \mathrm{~mm}$ aperture (Model U59730-30, Cole-Parmer International, USA). Colour was expressed in terms of CIE values for lightness $\left(\mathrm{L}^{*}\right)$, redness $\left(\mathrm{a}^{*}\right)$, and yellowness $\left(\mathrm{b}^{*}\right)$. The hue and chroma were measured using the $a^{*}$ and $b^{*}$ values (Young \& West, 2001). Chemical composition of the meat was determined using the procedures described by the AOAC (1990), using Kjeldahl for protein and lipid extraction for the ether extract. Dry matter was determined by drying the meat at $65^{\circ} \mathrm{C}$ for $24 \mathrm{~h}$ and ash was determined after ashing at $600{ }^{\circ} \mathrm{C}$.

Statistical analysis was performed utilising the general linear model (GLM) procedure of SAS (2000). The model was designed to determine the effect of treatment on parameters measured throughout the experiment. Initial weights were used as a covariate for the statistical analysis of body weights. Furthermore, a week effect was introduced into the model by a repeated measure designed to study growth behaviour and feed intake throughout the experiment. The model for weight gain and feed intake included the following:

$$
\mathrm{Y}_{\mathrm{ij}}=\mathrm{T}_{\mathrm{i}}+\mathrm{W}_{\mathrm{j}}+\operatorname{rep}\left(\mathrm{T}_{\mathrm{i}}\right)+\left(\mathrm{T}_{\mathrm{i}} * \mathrm{~W}_{\mathrm{j}}\right)+\text { residual error }
$$

where $\mathrm{T}=$ treatment and $\mathrm{W}=$ time (week).

The live fasting weight was used as a covariate for cold carcass weight, while cold carcass weight was used for the correction of the weight of the internal tissues and organs. Least square means for all variables in the study were calculated and the protected LSD test was used to determine significant differences (Steel \& Torrie, 1986). 


\section{Results and Discussion}

Mean monthly weights of calves in both groups in relation to the period of the treatment are shown in Figure 1. For the duration of the experiment no differences were observed in weight gains between the treated and untreated calves, though values tended to be higher for the yeast-supplemented calves. The difference in average gain was maximal during the first month, but decreased thereafter. The higher average gain during the first five months of the study might be related to a higher feed intake by the yeast-treated calves during the same period (listed below in Table 3) compared to the control calves. Erasmus et al. (1992) stated that one of the beneficial effects of the addition of yeast cultures to diets is enhancement of dry matter intake. The extra metabolisable energy obtained from the additional feed intake following yeast supplementation was sufficient to account for the increased production recorded (Wohlt et al., 1991). Feeding yeast culture of the same source (Diamond V) increased the palatability of feeds and consequently feed intake (Andrighetto et al., 1993).

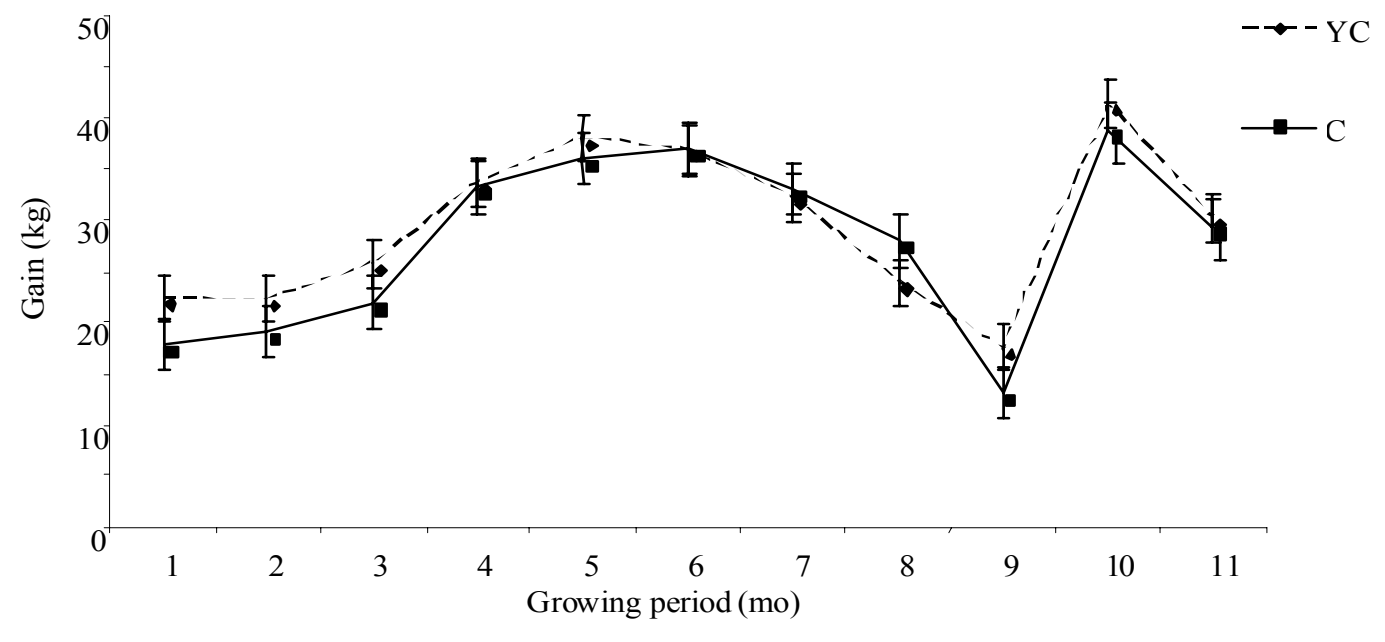

Figure 1 Mean monthly gain of calves fed yeast supplemented diets $\mathrm{YC}=$ yeast culture, $\mathrm{C}=$ control

Average gain started to decline during month 6 of the study, corresponding with the beginning of summer, and reached its lowest value during month 9 of the experiment. The decline occurred during the summer, i.e. between June and September, and was most evident during August and September when mean maximum ambient temperatures in the Jordan Valley were around 40 to $42{ }^{\circ} \mathrm{C}$. Feed intake was reduced during this period, which reduced average gain. Results of dry matter intake will be discussed later in this paper. However, Higginbotham et al. (1994) reported that yeast culture failed to reduce the heat stress of treated animals when supplemented during the summer period.

The results of final body weight, total gain and average daily gain are shown in Table 2. No differences were observed in final body weight between calves in both groups. Similarly, the results of total gain and average daily gain were not different between the treated and the non-treated calves.

Our results are in accordance with those of other workers who found that supplementing yeast culture had no effect on the growth rate of intensively fed bulls (Mutsvangwa et al., 1992; El Hassan et al., 1996; Beauchemin et al., 2003), grazing steers (Cabrera et al., 2000) or lambs (Kawas et al., 2007). Others reported that yeast culture tended to reduce the average daily gain of steers (Mir \& Mir, 1994) while Wehner et al. (1998) found that yeast-fed calves tended to gain more than the control calves. Contrary to this, other studies have shown that supplementation of yeast culture increased the average daily gain of calves (Cole et al., 1992; Olson et al., 1994) and lambs (Williams et al., 1987).

Total dry matter intake and average daily dry matter intake were lower $(\mathrm{P}<0.05)$ for the treated calves compared to those in the control group (Table 2). Intake values were affected by the conditions revealed during different periods of the study. Dry matter intake of the yeast-supplemented calves might have been 
confounded by the high temperature. These results are in contrast with those of other workers, who found that the addition of yeast culture to the diet of feeder calves and lambs resulted in a non-significant increase in feed consumption (Andrighetto et al., 1993), or found no differences in feed intake with yeast-treated lambs (Kawas et al., 2007), steers (Cabrera et al., 2000) or feedlot cattle (Beauchemin et al., 2003). However, other studies reported that yeast culture supplementation resulted in increased dry matter intakes of feeder calves (Cole et al., 1992), steers and bulls (Mutsvangwa et al., 1992; Andrighetto et al., 1993; Mir \& Mir, 1994; Olson et al., 1994; El Hassan et al., 1996).

Table 2 Effect of yeast culture supplementation on body weight (BW) gain, feed intake and feed conversion ratio of finishing dairy calves

\begin{tabular}{|c|c|c|c|}
\hline & \multicolumn{2}{|c|}{ Treatments } & \multirow[b]{2}{*}{ s.e. } \\
\hline & Control & Yeast culture & \\
\hline No. of animals & 15 & 15 & \\
\hline Average initial BW (kg) & 64.2 & 63.7 & \\
\hline Average final BW (kg) & 370.5 & 382.8 & 17.0 \\
\hline Total gain $(\mathrm{kg})$ & 306.3 & 319.2 & 14.2 \\
\hline Average daily gain (kg/day) & 1.04 & 1.08 & 0.05 \\
\hline Total dry matter intake $(\mathrm{kg})$ & $2895^{\mathrm{a}}$ & $2737^{b}$ & 40.3 \\
\hline Average dry matter intake $(\mathrm{kg} / \mathrm{d})$ & $9.9^{\mathrm{a}}$ & $9.3^{\mathrm{b}}$ & 0.1 \\
\hline Feed conversion ratio (FCR) & 9.5 & 8.7 & 0.4 \\
\hline Meat conversion ratio & 14.4 & 14.1 & 0.7 \\
\hline
\end{tabular}

Table 3 Effect of yeast culture supplementation on mean daily dry matter intake of dairy calves during different periods of the feeding period

\begin{tabular}{clcc}
\hline & \multicolumn{3}{c}{ Daily dry matter intake $(\mathrm{kg})$} \\
\cline { 2 - 4 } Period $^{1}$ & Control & Yeast culture & s.e. \\
\hline & $3.3^{\mathrm{b}}$ & & \\
1 & $4.0^{\mathrm{b}}$ & $4.2^{\mathrm{a}}$ & 0.21 \\
2 & $4.8^{\mathrm{b}}$ & $4.6^{\mathrm{a}}$ & 0.24 \\
3 & $5.9^{\mathrm{b}}$ & 4.7 & 0.38 \\
4 & 7.7 & $6.6^{\mathrm{a}}$ & 0.22 \\
5 & $9.7^{\mathrm{a}}$ & 7.7 & 0.41 \\
6 & 12.7 & $8.7^{\mathrm{b}}$ & 0.24 \\
7 & 14.0 & 10.9 & 0.34 \\
8 & 13.1 & 11.6 & 0.37 \\
9 & $12.8^{\mathrm{b}}$ & 12.5 & 0.41 \\
10 & 15.1 & $13.8^{\mathrm{a}}$ & 0.23 \\
11 & & 14.2 & 0.44 \\
\hline
\end{tabular}

\footnotetext{
${ }^{\mathrm{a} b}$ Means in a row with different superscripts are significantly different $(\mathrm{P}<0.05)$.

${ }^{1}$ Each period equals 28 days.
}

When comparing feed intakes during the different periods of the study (Table 3), calves in the yeastsupplemented group consumed more $(\mathrm{P}<0.05)$ total feed (on a dry matter basis) during the first five months than the control calves. Following that, calves in the control treatment consumed more feed during the last 
months, and feed intake of both groups was nearly equal. The higher feed intake of the yeast culture group during the first five months would have resulted in a higher heat increment in the body. When the summer heat came, such high intakes could be a disadvantage, probably explaining why no yeast culture effect on gain was observed in summer. Other workers indicated that yeast culture supplementation increased feed intake early but not late in the feeding period (Olson et al., 1994; Wohlt et al., 1998). According to Beauchemin et al. (2003), yeast culture was of limited value for feedlot cattle already adapted to high grain diets, because they were able to maintain relatively high feed intakes and digestion.

The diet used in our study was a high-concentrate diet for the finishing of cattle. According to Harrison et al. (1988) rumen fermentation is more stable in animals fed yeast culture than in unsupplemented animals. Several studies have suggested that yeast culture supplemented from the same source (Diamond V) affected the ruminal $\mathrm{pH}$ by increasing lactate utilisation by ruminal bacteria, which would result in the elimination of a lactate peak and the reduction of lactic acid concentrations in the rumen liquor (Piva et al., 1993; Lynch \& Martin, 2002). Thus, such stabilisation of the ruminal environment might have led to the expected improved digestibility and increased feed intake observed in the yeast-supplemented calves in the early stages of the study.

The feed conversion ratio was not different between treatments (Table 2). Furthermore, no differences were observed in meat conversion ratio expressed as $\mathrm{kg}$ of feed dry matter consumed per $\mathrm{kg}$ of meat produced based on cold carcass weight. This measurement was used as a better estimate for production than feed conversion ratio. The reason for no differences in feed conversion ratio could be due mainly to no differences in daily gain or total gain, although differences in feed intake were significant. Mutsvangwa et al. (1992) concluded that significant improvements in dry matter intake had no effects on the growth rate and

Table 4 Least-squares means for live weight, cold carcass weight, dressing percent, carcass and non-carcass components of dairy calves as influenced by yeast culture supplementation

\begin{tabular}{llll}
\hline & \multicolumn{2}{c}{ Treatments $^{1}$} & \\
\cline { 2 - 4 } & Control & Yeast culture & s.e. \\
\hline Characteristics & & & \\
Live fasting weight $(\mathrm{kg})$ & 364.3 & 365.5 & 7.8 \\
Cold carcass weight $(\mathrm{kg})$ & 187.8 & 184.2 & 0.8 \\
Dressing\% & 51.0 & 50.4 & 5.2 \\
Front quarters $(\mathrm{kg})$ & 88.0 & 86.2 & 4.9 \\
Hind quarters $(\mathrm{kg})$ & 99.8 & 98.0 & 0.7 \\
Weight (kg) of: & & & 0.6 \\
Hide & 25.2 & 25.7 & 0.2 \\
Head & 15.7 & 16.1 & 0.2 \\
Front feet & 4.4 & 4.6 & 0.7 \\
Rear feet & 4.7 & 4.8 & 0.3 \\
Total offal & 13.8 & 14.9 & 0.04 \\
Liver & 4.6 & 4.8 & 0.1 \\
Spleen & 0.6 & 0.7 & 0.3 \\
Heart & 1.4 & 1.6 & 0.1 \\
Lung & 4.4 & 4.2 & 0.3 \\
Kidney & 1.0 & 1.0 & 0.3 \\
Fore stomach & 8.5 & 7.7 & 0.3 \\
Small intestine & 5.8 & 6.6 & 0.5 \\
Large intestine & 4.9 & 4.5 & 0.1 \\
Kidney fat & 1.7 & 2.1 &
\end{tabular}

\footnotetext{
${ }^{1}$ Means between treatments not significantly different $(\mathrm{P}>0.05)$.

${ }^{2}$ Total offal includes liver, spleen, heart, lungs, kidneys, kidney fat and testis weights.
} 
efficiency of feed conversion of intensively fed bulls. Similar results were obtained by other workers, who reported no effect of feeding yeast cultures on feed conversion ratio in fattened bulls (Mutsvangwa et al., 1992), beef calves (Olson et al., 1994), or finishing lambs (Kawas et al., 2007).

No differences were observed in fasting live weight, cold carcass weight and dressing percentage between the treated and control calves (Table 4). Furthermore, all other carcass and non-carcass component measurements were not different between the two groups, except for the small intestinal weight, where there was a trend $(\mathrm{P}<0.10)$ for a higher weight in the treated calves.

Limited published literature is available on the effect of yeast culture supplementation on carcass and non-carcass characteristics. To our knowledge this is the first study to investigate the effect of yeast culture supplementation on dairy or beef calves in such details. Therefore, it is unfortunately difficult to interpret the present results. Higher values of some of the non-carcass component measurements for the yeast-treated calves (hide, head, rear and front feet and total offal) are reflected in lower cold carcass weights for those calves. In line with these results, other workers found no effect of yeast culture supplementation on carcass weights or dressing percentages of growing steers (Mir \& Mir, 1994), buffalo calves (Basiony et al., 1998) and lambs (Kawas et al., 2007).

No differences were observed in any of the rib-eye dimension measurements (Table 5). Back-fat thickness $(\mathrm{mm})$ over the M. Longissimus thoracis for yeast culture-treated calves was not significantly different from that of the control group. This could be attributed mainly to the similar growth and body weight gains obtained during the growing period. However, our results are in agreement with others, who reported no effect of yeast culture supplementation on the carcass traits of growing steers (Mir \& Mir, 1994) and buffalo calves (Basiony et al., 1998).

Table 5 Least-squares means of longissimus muscle dimensions and chemical composition of dairy calves as influenced by yeast culture supplementation

\begin{tabular}{llll}
\hline & \multicolumn{2}{c}{ Treatments ${ }^{1}$} \\
\cline { 2 - 3 } & Control & Yeast culture & s.e. \\
\hline Longissimus area $\left(\mathrm{cm}^{2}\right)$ & 24.7 & 22.8 & 1.4 \\
Longissimus width (mm) & 120.3 & 128.8 & 5.6 \\
Longissimus depth (mm) & 60.8 & 54.7 & 2.4 \\
Back-fat depth (mm) & 6.3 & 6.9 & 0.7 \\
Chemical composition (DM) \% & & & \\
$\quad$ Dry matter & 23.3 & 24.5 & 0.4 \\
Crude protein & 88.8 & 87.3 & 1.2 \\
Ether extract & 5.8 & 7.5 & 1.4 \\
Ash & 4.7 & 4.4 & 0.2 \\
\hline
\end{tabular}

${ }^{1}$ Means between treatments not significantly different $(\mathrm{P}>0.05)$.

The chemical composition measured in the total lean tissue of the longissimus muscle is also presented in Table 5. No differences were observed in chemical composition between both treatments. However, the lower protein content in the meat of the yeast culture-treated calves is probably an indication of an increased fat content of the muscle.

Least-squares means for meat quality characteristics of the longissimus muscle as influenced by yeast supplementation are presented in Table 6 . Muscle $\mathrm{pH}$ values measured at 2 and $4 \mathrm{~h}$ post mortem were lower $(\mathrm{P}<0.05)$ for the calves fed the supplemented diet. However, muscle $\mathrm{pH}$ values measured at 7 and $24 \mathrm{~h}$ post mortem and after thawing, and muscle temperature values measured at 2, 4, 7 and $24 \mathrm{~h}$ post mortem and after thawing there were no differences between the two treatments. Better meat quality, especially meat tenderness, is correlated with the rate of decline in $\mathrm{pH}$ and muscle temperature with time (Purchas, 1990). 
Table 6 Least-squares means for meat quality characteristics of dairy calves as influenced by yeast culture supplementation

\begin{tabular}{|c|c|c|c|}
\hline & \multicolumn{2}{|c|}{ Treatments } & \multirow[b]{2}{*}{ s.e. } \\
\hline & Control & Yeast culture & \\
\hline \multicolumn{4}{|l|}{$\begin{array}{l}\text { Characteristics } \\
\mathrm{pH} \text { after slaughter }\end{array}$} \\
\hline $2 \mathrm{~h}$ & $6.20^{\mathrm{b}}$ & $6.15^{\mathrm{a}}$ & 0.04 \\
\hline $4 \mathrm{~h}$ & $6.11^{\mathrm{b}}$ & $5.92^{\mathrm{a}}$ & 0.04 \\
\hline $7 \mathrm{~h}$ & 5.71 & 5.69 & 0.05 \\
\hline $24 \mathrm{~h}$ & 5.61 & 5.66 & 0.04 \\
\hline After thawing & 6.30 & 6.12 & 0.11 \\
\hline \multicolumn{4}{|c|}{ Temperatures after slaughter } \\
\hline $2 \mathrm{~h}$ & 25.90 & 25.95 & 0.2 \\
\hline $4 \mathrm{~h}$ & 19.45 & 19.50 & 0.2 \\
\hline $7 \mathrm{~h}$ & 5.77 & 5.80 & 0.11 \\
\hline $24 \mathrm{~h}$ & 3.55 & 3.70 & 0.15 \\
\hline WHC (\%) ${ }^{1}$ & 23.6 & 24.4 & 1.7 \\
\hline Cooking loss (\%) & 37.4 & 37.5 & 1.3 \\
\hline Shear force $(\mathrm{kg})^{2}$ & 5.60 & 5.95 & 0.5 \\
\hline Lightness (L*) & 32.7 & 35.5 & 1.44 \\
\hline Redness $\left(a^{*}\right)$ & 5.0 & 5.1 & 0.9 \\
\hline Yellowness $\left(b^{*}\right)$ & $17.1^{\mathrm{a}}$ & $11.5^{\mathrm{b}}$ & 0.3 \\
\hline Chroma & $18.0^{\mathrm{a}}$ & $13.5^{\mathrm{b}}$ & 1.8 \\
\hline Hue & 71.9 & 61.6 & 8.9 \\
\hline
\end{tabular}

In the present study the initial muscle $\mathrm{pH}$ values were recorded at $2 \mathrm{~h}$ post mortem. The rates of decline in muscle $\mathrm{pH}$ and temperature during the immediate post mortem period generally have a remarkable effect on meat tenderness, as muscles with a high $\mathrm{pH}$ at $3 \mathrm{~h}$ post mortem are slow to tenderise (Kannan et al., 2006).

There were no differences in water holding capacity (WHC) and cooking losses between the treated and control calves (Table 6). The term, WHC, was originally used to describe the ability of muscle and muscle products to bind water. Purchas (1990) reported an increase in WHC with increased live weights and fat content of animals.

No significant differences in shear force were recorded between the treatments (Table 6). Differences in shear force values could possibly be due to differences in the fat content of the muscle. However, such differences might be attributable to and explained by factors related to age, slaughter weight, nutrition, aging time, muscle type, time and temperature of cooking and ultimate $\mathrm{pH}$ (Purchas et al., 2002).

No differences were observed in lightness $\left(\mathrm{L}^{*}\right)$, redness $\left(\mathrm{a}^{*}\right)$ and hue values in muscles between the treated and control calves, with a trend for higher values in lightness and hue in the muscles of the treated calves $(\mathrm{P}=0.08)$. However, the muscles of yeast-supplemented calves had lower values $(\mathrm{P}<0.05)$ in yellowness $\left(b^{*}\right)$ and chroma compared to those of the control calves. This may indicate that the meat colour of muscles from yeast-supplemented calves was lighter and less red than that of the control calves. These differences might be due mainly to the higher intramuscular fat content observed in the muscles of yeastsupplemented calves compared to the control calves.

The reason for the variability in response to yeast culture supplementation between our study and others is not clear. Cole et al. (1992) reported that yeast culture could be beneficial to performance under some circumstances, with a considerable unexplained variability in response. This variability could be attributed to factors such as basal diet, viable cell number in the culture, amount of yeast supplemented, type 
of forage used and feeding strategy (Piva et al., 1993) and differences in ambient temperatures. Diet composition could affect the response to yeast culture supplementation (Williams et al., 1991). Mutsvangwa et al. (1992) reported that feeding a high-quality diet might not allow for any effect of yeast culture supplementation on performance. However, Beauchemin et al. (2003) concluded that yeast supplementation was of limited value for feedlot cattle already adapted to high grain diets, as they were able to maintain relatively high feed intakes and digestion.

In conclusion, the present findings indicated that the major effect of yeast culture supplementation was through its effect on feed intake. It had no influence on the growth rate and feed efficiency of finishing dairy calves. This would suggest that the effect of yeast culture in ruminants might be mediated through differences in the digestibility of nutrients in the rumen. Under the experimental conditions prevailing during this study, amongst others high temperature at stages, carcass characteristics and cooking values of the calves were not altered greatly with yeast supplementation.

\section{References}

Andrighetto, I., Bailoni, L., Cozzi, G. \& Berzaghi, P., 1993. Effects of yeast culture addition on digestion in sheep fed a high concentrate diet. Small Rumin. Res. 12, 27-34.

AOAC, 1990. Official Methods of Analysis $\left(15^{\text {th }}\right.$ ed.). Association of Official Analytical Chemists, Washington, D.C., USA.

Basiony, A.Z., Ragheb, E.E. \& Metwally, H.M., 1998. Effect of lasalocid and Yea-sacc supplementation on performance, digestibility and carcass characteristics of buffalo calves. Nutr. Abstr. Rev., Series B, 70, 3-4.

Beauchemin, K.A., Yang, W.Z., Morgavi, D.P., Ghorbani, G.R., Kautz, W. \& Leedle, J.A.Z., 2003. Effects of bacterial direct-fed microbial and yeast on site and extent of digestion, blood chemistry, and subclinical ruminal acidosis in feedlot cattle. J. Anim. Sci. 81,1628-1640.

Cabrera, E.J.I., Mendoza, M.G.D., Aranda, I.E., Garcia-Bojalil, C., Bárcena, G.R. \& Ramos, J.J.A., 2000. Saccharomyces cerevisiae and nitrogenous supplementation in growing steers grazing tropical pastures. Anim. Feed. Sci. Technol. 83, 49-55.

Cole, N.A., Purdy, C.W. \& Hutcheson, D.P., 1992. Influence of yeast culture on feeder calves and lambs. J. Anim. Sci. 70, 1682-1690.

El Hassan, S.M., Newbold, C.J., Edwards, I.E., Topps, J.H. \& Wallance, R.J., 1996. Effect of yeast culture on rumen fermentation, microbial protein flow from the rumen and live-weight gain in bulls given high cereal diets. Anim. Sci. 62, 43-48.

Erasmus, L.J., Botha, P.M. \& Kistner, A., 1992. Effect of yeast culture supplement on production, rumen fermentation, and duodenal nitrogen flow in dairy cows. J. Dairy Sci. 75, 3056-6065.

Geesink, G.H., Bekhit, A.D. \& Bickerstaffe, R., 2000. Rigor temperature and meat quality characteristics of lamb longissimus muscle. J. Anim. Sci. 78, 2842-2848.

Harrison, G.A., Hemken, R.W., Dawson, K.A. \& Harmon, R.J., 1988. Influence of addition of yeast culture supplement to diets of lactating cows on ruminal fermentation and microbial population. J. Dairy Sci. 71, 2967-2975.

Higginbotham, G.E., Collar, C.A., Aseltine, M.S. \& Bath, D.L., 1994. Effect of yeast culture and Aspergillus oryzae extract on milk yield in a commercial dairy herd. J. Dairy Sci. 77, 343-348.

Kannan, G., Gadiyaram, K.M., Galipalli, S., Carmichael, A., Kouakou, B., Pringle, T.D., McMillin, K.W. \& Gelaye, S., 2006. Meat quality in goats as influenced by dietary protein and energy levels, and postmortem aging. Small Rumin. Res. 61, 45-52.

Kawas, J.R., García-Castillo, R., Garza-Cazares, F., Fimbres-Durazo, H., Olivares-Sáenz, E., HernándezVidal, G. \& Lu, C.D., 2007. Effects of sodium bicarbonate and yeast on productive performance and carcass characteristics of light-weight lambs fed finishing diets. Small Rumin. Res. 67, 157-163.

Lynch, H.A. \& Martin, S.A., 2002. Effects of Saccharomyces cerevisiae culture and Saccharomyces cerevisiae live cells on in vitro mixed ruminal microorganism fermentation. J. Dairy Sci. 85, 2603-2608.

Mir, Z. \& Mir, P.S., 1994. Effect of the addition of live yeast (Saccharomyces cerevisiae) on growth and carcass quality if steers fed high-forage or high grain diets and on feed digestibility and in situ degradability. J. Anim. Sci. 72, 537-545. 
Mutsvangwa, T., Edwards, I.E., Topps, J.H. \& Paterson, G.F., 1992. The effect of dietary inclusion of yeast culture (Yea-Sacc) on patterns of rumen fermentation, food intake and growth of intensively fed bulls. Anim. Prod. 55, 35-40.

NRC, 2001. Nutrient Requirements of Dairy Cattle, $7^{\text {th }}$ rev. ed. National Research Council, Natl. Acad. Sci., Washington, D.C., USA.

Olson, K.C., Caton, J.S., Kirby, D.R. \& Norton, P.L., 1994. Influence of yeast culture supplementation and advancing season on steers grazing mixed-grass prairie in the northern Great Plains: I. Dietary composition, intake, and in situ nutrient disappearance. J. Anim. Sci. 72, 2149-2157.

Piva, G., Belladonna, S., Fusconi, G. \& Sicbladi, F., 1993. Effects of yeast culture on dairy cow performance, ruminal fermentation, blood components, and milk manufacturing properties. J. Dairy Sci. 76, 2717-2722.

Purchas, R.W., 1990. An assessment of the role of $\mathrm{pH}$ differences in determining the relative tenderness of meat from bulls and steers. Meat Sci. 27, 129-140.

Purchas, R.W. \& Aungsupakorn, R., 1993. Further investigations into the relationship between ultimate pH and tenderness for beef samples from bulls and steers. Meat Sci. 34, 163-178.

Purchas, R.W., Burnham, D.L. \& Morris, S.T., 2002. Effects of growth potential and growth path on tenderness of beef longissimus muscle from bulls and steers. J. Anim. Sci. 80, 3211-3221.

Sañudo, C., Sierra, I., Lopez, M. \& Forcada, F., 1986. The quality of the ovine meat, study of the various factors which condition it. Commission des C. E. Rapport EUR (11479) 67-81.

SAS, 2000. Statistical Analysis System user's guide, Ver. 7. SAS Institute Inc., Cary, N.C., USA.

Steel, G.D.R. \& Torrie, H.J., 1986. Principles and Procedures of Statistics. $2^{\text {nd }}$ ed. NewYork, McGraw-Hill.

Van Soest, P.J. \& Robertson, J.B., 1980. Systems of analysis for evaluating fibrous feeds. In: Standardization of Analytical Methodology for Feeds. Eds. Pigden, W.J., Balch, C.C. \& Graham, M., Ottowa, Canada, Int. Res. Dev. Ctr. Pub. No. 134e.

Wehner, G.R., Brokaw, L., Gamett, J.E. \& Zidon, J., 1998. Effect of yeast culture inclusion in ad libitum trace mineralized salt on cow and calf performance. J. Anim. Sci. (Suppl. 1), 34.

Williams, J.E., Grabing, S., Miller, S.J. \& Gieseke, L., 1987. The influence of supplemental yeast culture and sodium bicarbonate on performance and blood acid-base status in wether lambs exposed to elevated ambient temperature. J. Anim Sci. (Suppl. 1) 65, 156 (Abstr.).

Wohlt, J.E., Corcione, T.T. \& Zajac, P.K., 1998. Effect of yeast on feed intake and performance of cows fed diets based on corn silage during early lactation. J. Dairy Sci., 81, 1345-1352.

Wohlt, L.E., Finkelstein, A.D. \& Chung, C.H., 1991. Yeast culture improves intake, nutrient digestibility, and performance by dairy cattle during early lactation. J. Dairy Sci. 74, 1395-1400.

Young, O.A. \& West, J., 2001. Meat color. In: Meat Science and Applications. Eds. Hui, Y.H., Nip, W.K., Rogers, R.W. \& Young, O.A., Marcel Dekker, New York, USA. 